\title{
Neuropsychology across the Lifespan: Proceedings of the Third Meeting of the Federation of European Societies of Neuropsychology
}

\author{
Radek Ptak $^{\mathrm{a}, \mathrm{b}, *}$ and Guy Vingerhoets ${ }^{\mathrm{c}}$ \\ ${ }^{a}$ Division of Neurorehabilitation, Department of Clinical Neurosciences, Geneva University Hospitals, Geneva, \\ Switzerland \\ ${ }^{\mathrm{b}}$ Medical School, University of Geneva, Geneva, Switzerland \\ ${ }^{\mathrm{c}}$ Department of Experimental Psychology, Ghent University, Ghent, Belgium
}

The Third Meeting of the Federation of European Societies of Neuropsychology (ESN) took place at the Congress Centre in Basel, Switzerland, from 7-9 September 2011. The theme of this meeting, which assembled more than 400 clinicians and researchers from many European countries as well as from North America, Asia and Australia, was 'Neuropsychology across the Lifespan'. This theme gave the opportunity to discuss a large range of current neuropsychological topics pertaining to different developmental stages and age groups. We are grateful to the Editors of Behavioural Neurology, Argye Hillis-Trupe and Stefano Cappa, to give us the opportunity to present here a selection of individual contributions in a condensed format. The studies described here were included as oral presentations in one of four sessions: Reading and Alexia (Starrfelt et al., Auclair-Ouellet et al.), Space and Action (van der Ham et al., Bonato et al.), Plasticity and Rehabilitation (Sedda et al., Dubovik et al., Gutiérrez Iglesias et al., Duits et al.), and Memory and Amnesia (van Geldorp et al., Marques, Barban et al., Jonin et al., El Haj et al.). We hope these excellent contributions motivate you to participate to one of the future meetings of the ESN.

\footnotetext{
* Corresponding author: Radek Ptak, Division of Neurorehabilitation, Geneva University Hospitals and Faculty of Medicine, University of Geneva, 26, Av. de Beau-Séjour, 1211 Geneva 14, Switzerland. Tel.: +41 2238235 24; Fax: +41 2238283 38; E-mail: radek. ptak@hcuge.ch.
} 


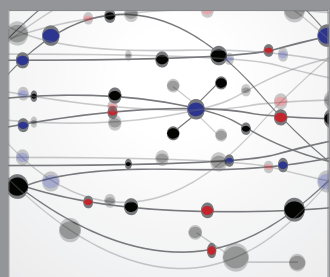

The Scientific World Journal
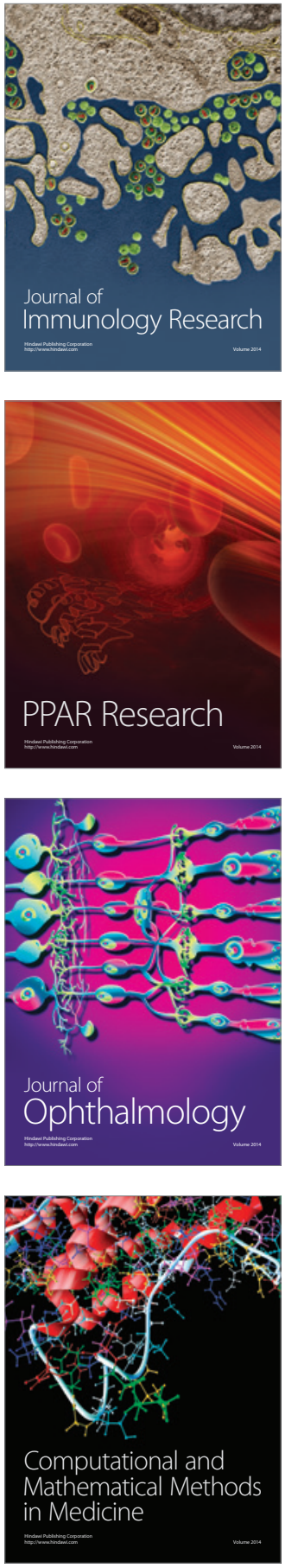

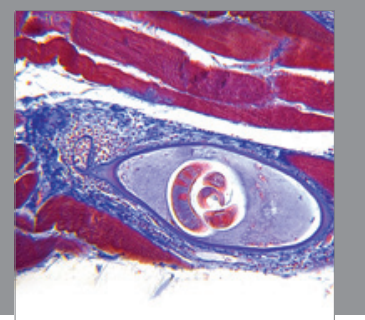

Gastroenterology

Research and Practice
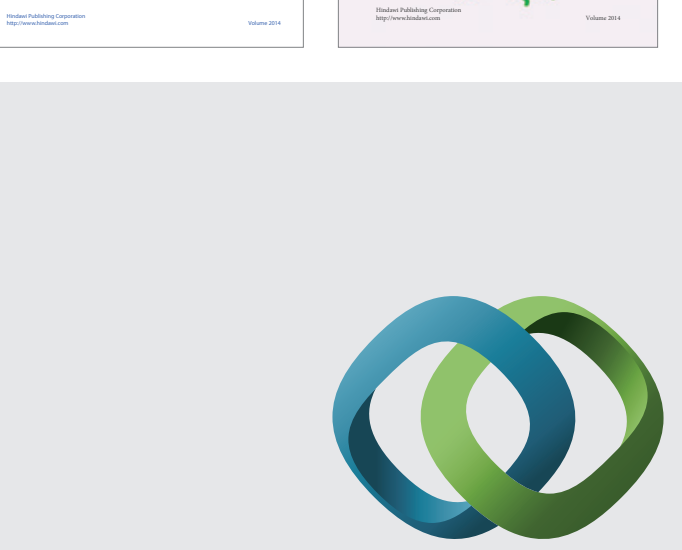

\section{Hindawi}

Submit your manuscripts at

http://www.hindawi.com
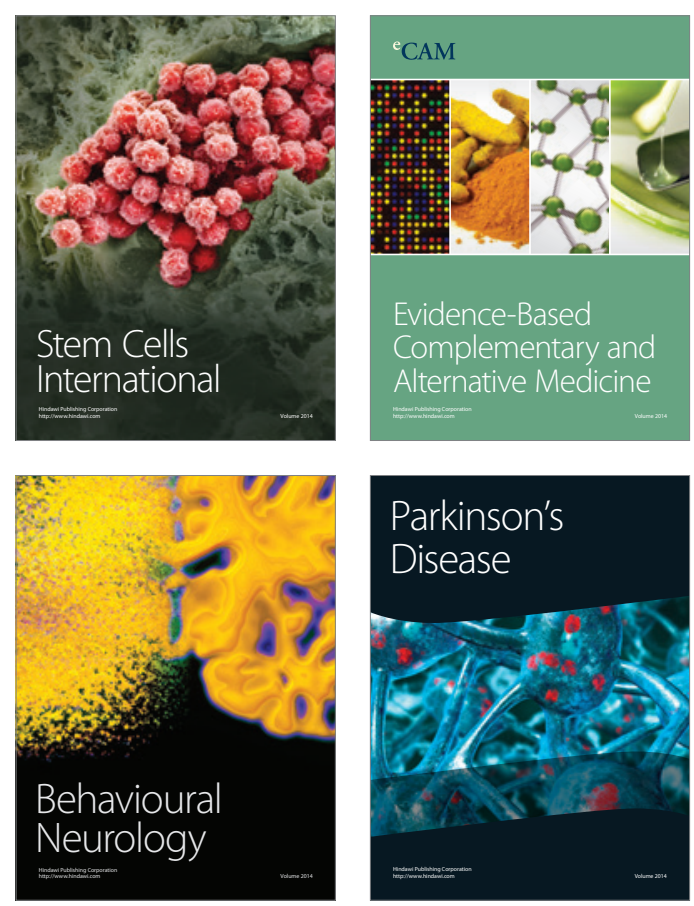

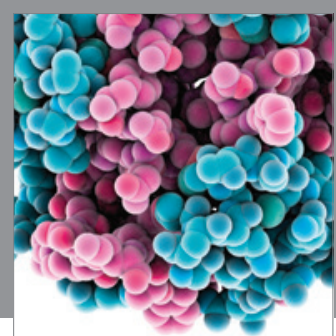

Journal of
Diabetes Research

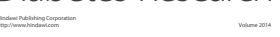

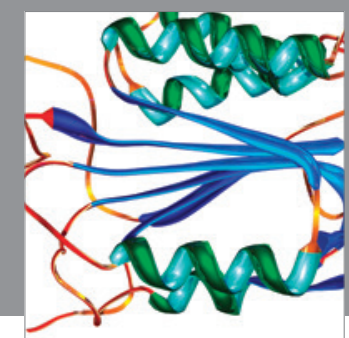

Disease Markers
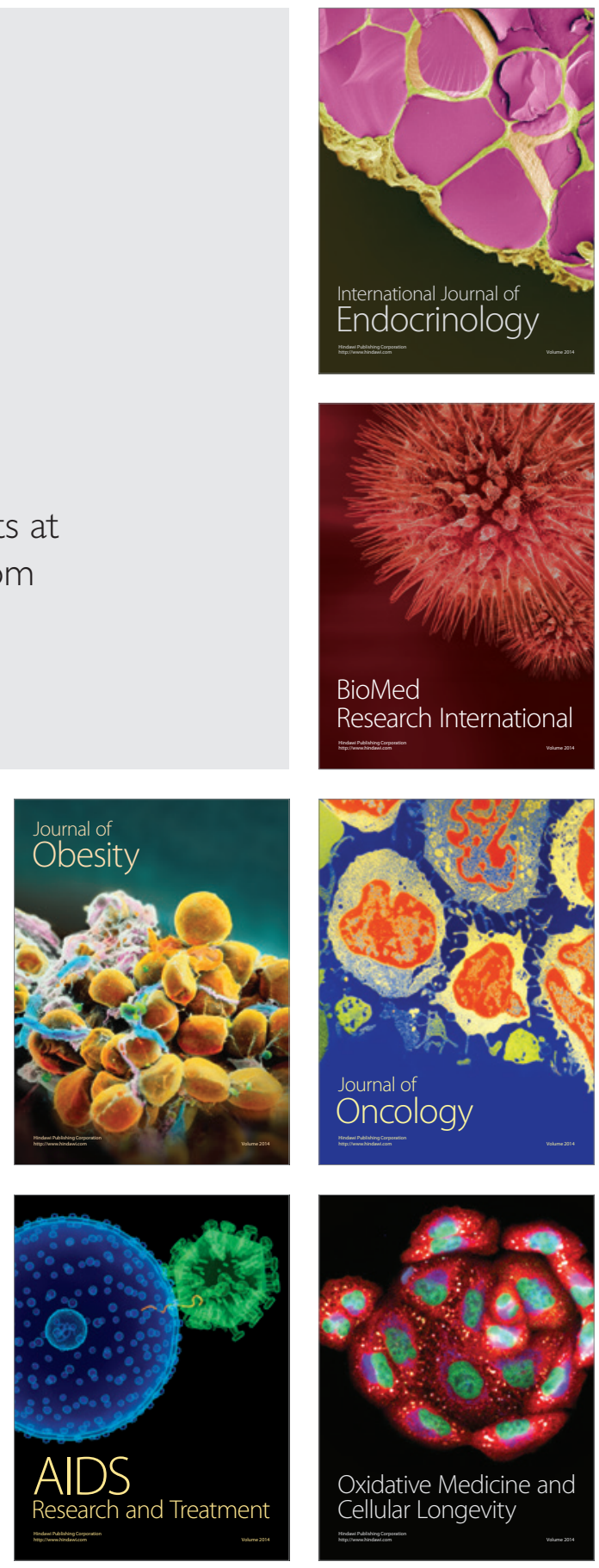